\title{
Isolation and Functional Characterization of Schwann Cells Derived from Adult Peripheral Nerve
}

\author{
Thomas K. Morrissey, Naomi Kleitman, and Richard P. Bunge \\ The Miami Project to Cure Paralysis, and the Department of Neurological Surgery, University of Miami School of \\ Medicine, Miami, Florida 33136
}

\begin{abstract}
To facilitate the development of autologous transplantation techniques with which to test the ability of Schwann cell (ScC) implantations to treat nervous system injury, we have developed a method for procuring large, essentially pure populations of ScCs from adult peripheral nerve. By allowing small explants of peripheral nerve trunk to undergo axonal and myelin breakdown in vitro, rather than dissociating the nerve immediately after harvest, we are able to (1) rid the explant of nearly all fibroblasts and (2) capitalize on the intrinsic ScC mitogenic response to peripheral nerve degeneration. Here, we describe a method that yields up to $98 \%$ pure ScC populations from adult rat sciatic nerve (based on cell soma and nuclear morphology, $\$ 100$ staining, and behavior of dissociated cells on neurites) at cell yields of greater than $2 \times 10^{4}$ cells $/ \mathrm{mg}$ of starting nerve weight. The purification technique was successfully applied to human tissue; human phrenic nerve yielded $98 \%$ pure ScC populations at cell yields of $2 \times 10^{4}$ cells $/ \mathrm{mg}$ of initial nerve weight. Similar to neonatally derived ScCs, adult rat cells can be expanded in coculture with dorsal root ganglion (DRG) neurons or in isolation in the presence of glial growth factor and forskolin. Cells expanded indefinitely on DRG neurons, or up to 10 weeks on chemical mitogens, return to quiescence following removal of the mitogenic stimulus. Expanded adult-derived rat ScCs retain functional capacity, as evidenced by their ability to myelinate DRG neurites and to support regeneration of processes from embryonic rat retinal explants.
\end{abstract}

Early in the last decade, landmark experiments by Aguayo and colleagues (Richardson et al., 1980; David and Aguayo, 1981) demonstrated that peripheral nerve grafts could support central neuronal regeneration in vivo. Many subsequent studies have indicated that the ability of the peripheral nerve milieu to support regeneration may be a function of the Schwann cell $(\mathrm{ScC})$, particularly of its surface molecules (Noble et al., 1984; Fallon, 1985a,b; Ard et al., 1987; Bixby et al., 1988; Kleitman et al.,

\footnotetext{
Received Dec. 3, 1990; revised Feb. 25, 1991; accepted Mar. 11, 1991.

This work was supported by The Miami Project to Cure Paralysis, University of Miami School of Medicine, and the National Institute of Neurological Disease and Stroke, National Institutes of Health, Grant NS19923. We thank Cynthia Ferrendelli and Margaret Bates for excellent technical assistance, Les Olson and the University of Miami transplant team for supplying human tissue, and Melitta Schachner for the generous gift of anti- $P_{0}$.

Correspondence should be addressed to Dr. Morrissey, The Miami Project, University of Miami School of Medicine, 1600 N.W. 10th Ave., R-48, Miami, FL 33136.

Copyright (C) 1991 Society for Neuroscience 0270-6474/91/112433-10\$03.00/0
}

1988; Bunge and Hopkins, 1990; for review, see Fawcett and Keynes, 1990). The preparation of large, stable, and fully functional populations of ScCs using tissue culture techniques has led to the design of cellular prostheses that may favorably influence repair following CNS injury (Kromer and Cornbrooks, 1985). Such ScC populations are generally prepared from prenatal or neonatal PNS tissues (Wood, 1976; Brockes et al., 1979). In a clinically relevant paradigm, however, availability of donor tissue becomes a central issue and dependence on perinatal tissue is problematic. Autologous grafting would eliminate the problem of finding compatible donors as well as alleviate the rejection sequellae often associated with transplantation. In most cases, autotransplantation would require preparation of $\mathrm{ScCs}$ from adult nerve obtained at biopsy. We were thus interested in comparing techniques that might be useful in obtaining pure populations of $\mathrm{ScCs}$ from adult peripheral nerve, and in exploring methods to expand these populations while retaining growth control and functional capacity.

It is substantially more difficult to extract ScCs from adult nerve than from embryonic or perinatal nerve because the adult tissue contains a more fully developed epineurium and perineurium composed of fibroblast (FB)-derived cells (Bunge et al., 1989) and substantial amounts of connective tissue within these layers as well as in the endoneurium (Bunge, 1986). Dissociation of perinatal sciatic nerves yields populations with a high percentage of ScCs, and subsequent treatment with antimitotic agents can remove the few remaining FBs (Brockes et al., 1979). Conversely, dissociation of adult rat sciatic nerve results in relatively poor yields and a substantially higher percentage of FBs that cannot easily be eliminated by antimitotic agents. Within a few days in vitro, the FBs often outgrow and overtake the ScC population. Scarpini et al. (1988) have reported a method utilizing slow enzymatic digestion of peripheral nerve in a serum-containing enzyme solution that is effective in increasing the $\mathrm{ScC}$ / FB ratio in nerves treated immediately after dissection. This method yields, however, only about 600 cells $/ \mathrm{mg}$ of dissociated nerve. Askanas et al. (1980) have shown that adult ScC populations can be enhanced greatly by placing pieces of peripheral nerve in culture and, as FBs migrate out onto the substratum, removing the nerve explants to new culture dishes. After a number of such passages, the explants are relatively depleted of FBs and the majority of the cells migrating out onto the substratum are then ScCs. This method, in which only the cellular outgrowth is harvested, requires a culture period of up to 14 weeks to obtain sufficient cells to perform biochemical assays (Reddy et al., 1982). Specific cell yields were not stated in earlier publications. 
In the present study, we have reexamined both of these strategies and report that by combining some aspects of each, we are able to take advantage of the amplification and purification aspects of the Askanas method while maximizing cell yield by late dissociation of the explants. The combination of these methods yields large numbers of highly purified ScCs. We demonstrate that these cells retain functionality (i.e., the ability to myelinate axons and support neurite growth) and can be further expanded in culture for use in tissue culture experiments or in transplantation paradigms.

\section{Materials and Methods}

\section{Purification technique comparison}

Tissue was obtained from adult Sprague-Dawley rats under aseptic conditions. The animals were killed by ether inhalation, and their sciatic nerves were dissected out and placed into Liebovitz's L-15 medium (GIBCO) supplemented with $50 \mathrm{U} / \mathrm{ml}$ penicillin and $0.05 \mathrm{mg} / \mathrm{ml} \mathrm{strep-}$ tomycin (L-15a). After the epineurium, connective tissue, and blood vessels were stripped off with fine forceps, each nerve was $3-4 \mathrm{~cm}$ long and weighed $20-30 \mathrm{mg}$. The nerves were placed in fresh L-15a and minced with scissors or scalpel blades into roughly $1 \times 1-\mathrm{mm}$ explants. We compared cell yields from nerve that was dissociated immediately versus nerve that was carried through a series of sequential explantations in vitro prior to dissociation.

Dissociation. Following the procedure described by Pleasure et al. (1986), the minced nerves were placed in a $35-\mathrm{mm}$ dish containing 1.25 $\mathrm{U} / \mathrm{ml}$ dispase (Boehringer Mannheim Biochemicals), $0.05 \%$ collagenase (Worthington Biochemicals Corp.), 15\% fetal calf serum (FCS), and 25 mм HEPES in Dulbecco's Modified Eagle's Medium (DMEM); (GIB$\mathrm{CO}$ ). The tissue in this solution was triturated in a Pasteur pipette approximately 10 times and was then incubated overnight at $37^{\circ} \mathrm{C}$ in $7 \% \mathrm{CO}_{2}$. The following day, the explants were dissociated by gentle trituration through a flame-narrowed borosilicate pipette $(0.5-1-\mathrm{mm}$ bore), washed 2-3 times in DMEM/10\% FCS, and seeded onto polylysine-coated glass coverslips.

Multiple explantation. Ten to fifteen pieces of sciatic nerve were placed as explants into $35-\mathrm{mm}$ tissue culture plastic dishes with low levels of DMEM $/ 10 \%$ FCS $(750 \mu 1 /$ dish). The medium level was kept low during the initial plating to prevent the explants from floating off the surface of the culture dish; once the explants had attached, the medium level was raised and the medium was replaced twice a week with fresh DMEM/ $10 \%$ FCS. The explants were examined several times a week for the emergence of migratory cells. As there were no neurons in the explants, and thus no neurite extension, the outgrowth was entirely cellular. When the outgrowth around the explants reached a near-confluent monolayer (7-10 d), the explants were lifted off the surface of the culture dish with fine forceps and placed in new dishes with fresh medium. This was continued for approximately 4-5 weeks, at which time the cells forming the outgrowth were primarily ScCs. The explants were then removed to a fresh $35-\mathrm{mm}$ dish, dissociated following enzymatic digestion, and plated as described above.

ScCs were identified in living cultures on the basis of cell soma and nuclear morphology using phase contrast microscopy. Cells with long bi- or tripolar processes (that were approximately 5-7 times the width of the cell body) and oval nuclei were counted as ScCs while FBs (the only other abundant cell type) were identifiable by a much more flattened polymorphic shape with larger round nuclei. In fixed cultures, $\mathrm{ScCs}$ were identified by immunocytochemical labeling for $\mathrm{S} 100$ protein. Cells were fixed for $10 \mathrm{~min}$ in $4 \%$ paraformaldehyde followed by permeabilization in $4 \%$ paraformaldehyde with $0.02 \%$ Triton X-100. After blocking with L-15/10\% heat-inactivated horse serum (HIHS), the cells were incubated with anti-S100 (1:100; Dakopatts) overnight at $4^{\circ} \mathrm{C}$. The following day, the cells were incubated with fluorescein-conjugated goat antirabbit (1:100; Cappel/Organon Teknika Corp.) for $30 \mathrm{~min}$ at room temperature. Slides were mounted in a glycerol/PBS solution (Citifluor Ltd.) containing $5 \mu \mathrm{M}$ Hoechst dye (Hoechst 33342; Sigma). After intercalation of Hoechst dye into the DNA, we visualized nuclei under fluorescence microscopy.

\section{Amplification of Schwann cells}

In order to amplify the $\mathrm{ScC}$ populations, the cells were grown on either dorsal root ganglion (DRG) neuron preparations or on polylysine-coated tissue culture plastic in the presence of glial growth factor (GGF) and forskolin (Porter et al., 1986).

Neuronal preparations. Neuronal preparations consisted of dissociated DRG cells as described previously (Wood, 1976) except that trypsin-dissociated cultures were used instead of intact ganglia. Briefly, E-15 rat DRGs were dissociated in $0.1 \%$ trypsin and seeded into the center of a $25-\mathrm{mm}$ collagen-coated Aclar dish (Bunge et al., 1988). Treatment with the antimitotic agent fluorodeoxyuridine eliminated all proliferating cells, leaving behind only the postmitotic neurons. These were allowed to extend neurites for 2-3 weeks in Eagle's Minimal Essential Medium (GIBCO) supplemented with $10 \%$ FCS, $496 \mathrm{mg} \% \mathrm{glu}$ cose, $100 \mathrm{ng} / \mathrm{ml}$ NGF (Boehringer Mannheim Biochemicals). Each DRG culture was seeded with 5-7 $\times 10^{4}$ adult $\mathrm{ScCs}$ prepared by the methods described above and maintained in serum-free N2 medium (modified from Bottenstein and Sato, 1979; Eldridge et al., 1987) at $35^{\circ} \mathrm{C}$ in a humidified $5 \% \mathrm{CO}_{2}$ atmosphere. Cultures were refed three times a week. When the neurites became fully populated (about 15-18 d), the centers of the cultures, containing the neuronal cell bodies, were cut out with a razor blade fragment and removed. The remaining neurite and $\mathrm{ScC}$ beds were then carefully lifted off the collagen substratum with fine forceps and placed in $0.05 \%$ trypsin for $30 \mathrm{~min}$ at $37^{\circ} \mathrm{C}$. Cells were then washed twice in DMEM/10\% FCS and gently triturated; samples were counted in a hemacytometer, and the cells were again seeded onto DRG neuron preparations, as above $\left(5-7 \times 10^{4} \mathrm{ScCs} /\right.$ culture $)$, for continued expansion.

For expansion in the presence of GGF, $5 \times 10^{5} \mathrm{ScCs}$ were seeded onto polylysine-coated $100-\mathrm{mm}$ tissue culture plastic dishes in DMEM/ $10 \%$ FCS. Cells were allowed to attach overnight, and the cultures were refed with DMEM/10\% FCS supplemented with $20 \mu \mathrm{g} / \mathrm{ml} \mathrm{GGF}$ and 2 $\mu \mathrm{M}$ forskolin. Cultures were monitored several times a week, but the medium was not changed. When the cultures reached confluency (7-10 d), the cclls were passaged. Cells were removed from the dishes by rinsing several times in $\mathrm{Ca}^{2+}$ and $\mathrm{Mg}^{2+}$-free Hanks balanced salt solution(CMF) and $0.02 \%$ EDTA, followed by brief treatment with $0.05 \%$ trypsin/ $0.02 \%$ EDTA in CMF. Cells were washed twice in DMEM $/ 10 \%$ FCS and replated onto new polylysine-coated dishes for further expansion.

To test for retention of proliferative control (absence of transformation), samples of cells from each of the two expansion groups were replated (at various passages) onto polylysine-coated dishes and maintained in the absence of any added extrinsic mitogens. Cultures were maintained for 3-4 weeks and observed for the appearance of clones of proliferating cells.

Proliferation rates in both amplification conditions and the growth control tests were assessed by tests of bromodeoxyuridine (BrdU) incorporation (Yong and Kim, 1987). Briefly, cultures were incubated for $24 \mathrm{~h}$ in DMEM $/ 10 \%$ FCS supplemented with $10 \mu \mathrm{M}$ BrdU (Sigma). Cells were then incubated for $15 \mathrm{~min}$ in BrdU-free medium followed by several rinses with L-15. The cultures were then fixed for $20 \mathrm{~min}$ in $70 \%$ ethanol at $-20^{\circ} \mathrm{C}$. After rehydration with $\mathrm{L}-15$, the cultures were treated with $2 \mathrm{~N} \mathrm{HCl}$ (10 min at room temperature) to denature the DNA. This step was necessary because the antibody against BrdU will only bind to single-stranded DNA. The acid was neutralized by rinsing with L-15 followed by a $10-\mathrm{min}$ incubation in $0.15 \mathrm{M}$ borate buffer $(\mathrm{pH}$ 8.4). The cultures were incubated overnight at $4^{\circ} \mathrm{C}$ in $\mathrm{L}-15 / 5 \%$ HIHS containing anti-BrdU (1:100; Becton Dickinson) and anti-S100 (1:100). The following day, the cultures were rinsed and incubated for $30 \mathrm{~min}$ at room temperature with rhodamine-conjugated goat anti-mouse (1: 50) and fluorescein-conjugated goat anti-rabbit (1:100). Cultures were then rinsed and mounted as described above.

\section{Functionality assessment}

Myelination. To test the ability of the amplified $\mathrm{ScC}$ populations to relate to neuronal surfaces, cells from each of the amplification groups were periodically seeded onto DRG neurite beds. Cocultures were maintained in N2 medium, and ScCs were observed for association with neurites in preference to the underlying collagen substratum. To assess the ability of the ScCs to form myelin, the ScCs were allowed time to repopulate the neuronal surfaces in N2 medium, and then the medium was changed to a myelination-supporting medium (with $15 \%$ FCS and ascorbate; Eldridge et al., 1987) and refed three times a week. Cultures were monitored several times a week for the appearance of myelin segments.

To better visualize myelin formed in the cultures, selected cultures were immunostained for the myelin-specific marker, $\mathrm{P}_{0}$. Briefly, cultures 


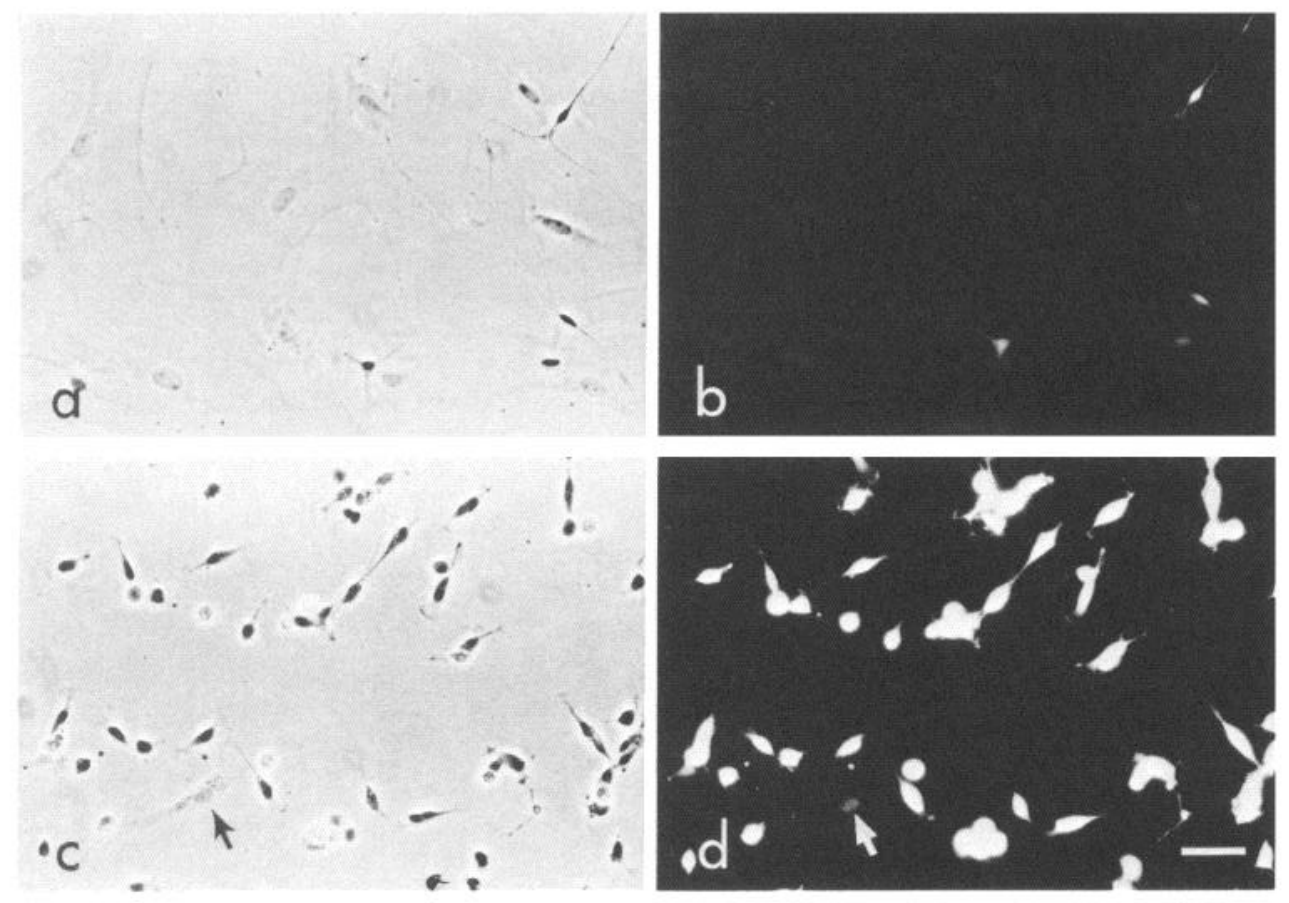

Figure 1. Representative cell yield (24 hr after plating) following immediate dissociation of adult rat sciatic nerve ( $a$ and $b$ ) and following four reexplantations in $33 \mathrm{~d}(c$ and $d) . a$ and $c$, Phase contrast; $b$ and $d, \mathrm{~S} 100$ immunostaining. Note unstained FB in panels $c$ and $d$ (arrows). Scale bar, $50 \mu \mathrm{m}$. were rinsed in L-15 and fixed in $5 \%$ acetic acid $/ 95 \%$ ethanol for $10 \mathrm{~min}$ at $-20^{\circ} \mathrm{C}$. After rinsing in $0.1 \mathrm{M}$ phosphate buffer and blocking in L-15/10\% HIHS, the cultures were incubated in anti- $\mathrm{P}_{\text {o }}$ (full-strength supernatant; generous gift of M. Schachner, University of Heidelberg) for $30 \mathrm{~min}$ at room temperature. The cultures were then rinsed and incubated for $30 \mathrm{~min}$ at room temperature in fluorescein-conjugated goat anti-rabbit (1:100). Cultures were mounted as above. For detailed light microscopic examination, some cultures were stained with Sudan black as described by Wood (1976). Cultures were fixed overnight in $2 \%$ glutaraldehyde in $0.05 \mathrm{M}$ phosphate buffer with $0.1 \mathrm{M}$ sucrose and then osmicated in $1 \% \mathrm{OsO}_{4}$ in $0.1 \mathrm{M}$ phosphate buffer for $1 \mathrm{hr}$, rinsed, dehydrated, and stained in $0.5 \%$ Sudan black in $70 \%$ ethanol. After gradual rehydration, cultures were washed with phosphate buffer and mounted in glycerine jelly.

Support of CNS neurite growth. To test the ability of expanded $\mathrm{ScCs}$ to support neurite growth, embryonic day 15 rat retina was plated onto $\mathrm{ScC}$ cultures as described previously (Kleitman et al., 1988). Briefly, 25-mm collagen-coated Aclar dishes were seeded with $5 \times 10^{5} \mathrm{GGF}$ and forskolin-expanded $\mathrm{ScCs}$ and allowed to settle in culture for $4 \mathrm{~d}$. Eyes were removed aseptically from E-15 rats, and retinas were dissected free. Retinas were cut into thirds radially from the optic disk outward and were plated either onto the $\mathrm{ScC}$ beds or onto control dishes coated with ammoniated collagen. Cultures were kept at $37^{\circ} \mathrm{C}$ in EMEM supplemented with $10 \%$ FCS, $496 \mathrm{mg} \%$ glucose, $100 \mathrm{ng} / \mathrm{ml}$ NGF. After 5 $\mathrm{d}$, the cultures were fixed. Some cultures were stained with Sudan black as above to aid in visualization of neurites at the light microscopic level. The remaining cultures were immunostained with the neurofilamen antibody SMI-31 (Sternberger-Meyer Immunochemicals, Inc.) and antiS100. S100 staining was conducted as above. For SMI-31 staining, the cultures were fixed in $4 \%$ paraformaldehyde in $0.1 \mathrm{~m}$ phosphate buffer followed by permeabilization in $95 \%$ ethanol, $5 \%$ acetic acid $\left(-20^{\circ} \mathrm{C}\right.$, $10 \mathrm{~min})$. These were then incubated with SMI-31 (1:1000; $30 \mathrm{~min}$ at room temperature) followed by rhodamine-conjugated goat anti-mouse secondary.

\section{Human tissue}

To test the applicability of these techniques to adult human peripheral nerve, some of the above procedures were repeated using postmortem samples of human phrenic nerve. Human tissue was obtained by a transplant procurement team from organ donors within $30 \mathrm{~min}$ of death and was transported within $4 \mathrm{hr}$ to the laboratory in RPMI medium on wet ice. Two separate samples were taken with wet unstripped weights of 145 and $250 \mathrm{mg}$. Donors were tested serologically and were free of contagious diseases and diseases associated with peripheral neuropathies, such as diabetes mellitus. Using procedures identical to those described above, some tissue was dissociated immediately and some was carried through multiple explantations before dissociation. Human ScCs were examined by phase contrast microscopy and also immunostained for $\mathrm{S} 100$ as described above.

\section{Results}

\section{Rat tissue}

\section{Immediate dissociation versus multiple explantation}

Immediate dissociation of rat sciatic nerve yielded about $1 \times$ $10^{3}$ cells/mg of nerve. Examination $24 \mathrm{hr}$ after plating revealed that some distinctly bipolar ScCs could be seen among the dissociated cells, but flat polymorphic FBs were the predominant cell type. Counting of S100-labeled cells showed that ScCs made up only $10-40 \%$ of the total cell number (Fig. $1 a, b$ ). In contrast, when the pieces of nerve that had been multiply explanted were dissociated and plated, at least $97 \%$ of the cells showed bi- or tripolar morphology and stained positively with $\mathrm{S} 100$ (Fig. 1c,d). Cell yields from explants varied widely. In all cases, however, yields were over 20 times greater than those observed after immediate dissociation. Table 1 shows total cell yields and percentage of ScCs from both the immediate dissociation and multiple explantation experiments. Cell yields without complement treatment ranged from $4 \times 10^{4}$ to $1.35 \times 10^{5}$ cells $/ \mathrm{mg}$ dissociated nerve. Given the high percentage of ScCs in the explanted groups, the comparative $\mathrm{ScC}$ yields in explanted material were often more than two orders of magnitude greater than after immediate dissociation.

Appearance of explants. Explants appeared as dark clumps at the light microscopic level. Individual myelinated segments were often visible at the edges of the explants, suggesting that the epineurium had been completely removed. Migration of cells out of the nerve explants was first seen between 2 and $4 \mathrm{~d}$ after the tissue was first placed in culture. The first cells seen were almost always flat polymorphic FBs (Fig. 2a), and they tended 
Table 1. Comparison of yields from immediate dissociation versus dissociation following multiple explantation

\begin{tabular}{lccc} 
& $\begin{array}{l}\text { Days } \\
\text { in } \\
\text { culture }\end{array}$ & $\% \mathrm{~S} 100+$ & $\begin{array}{l}\text { Total cell } \\
\text { yield } \\
\text { (cells/mg) }\end{array}$ \\
\hline Immediate dissociation & 1 & 15 & $\mathrm{ND}^{a}$ \\
& 1 & 28 & 1065 \\
Dissociation following & 1 & 35 & 600 \\
multiple explantation & 32 & 98 & 135,614 \\
& $33^{b}$ & 73 & $\mathrm{ND}$ \\
& 36 & 98 & $\mathrm{ND}$ \\
& $39^{c}$ & 98 & $\mathrm{ND}$ \\
& 41 & 98 & 42,930 \\
& $41^{c}$ & 98 & 19,037
\end{tabular}

${ }^{a} \mathrm{ND}$, Counts not done.

"Outgrowth still contained FBs at the time of explant dissociation.

Treated with anti-Thy- 1 and complement.

to migrate away from the explants and proliferate on the plastic substratum. By the end of the first week in culture, the FBs constituted a near monolayer of cells surrounding the explants (Fig. 2b). Explants containing significant numbers of macrophages tended to disintegrate within the first 2 weeks, making them impossible to reexplant. These explants (less than $10 \%$ of the total) were therefore eliminated from the experiments. Serial explantation of remaining explants elicited a gradual change in the number and types of cells migrating out from the tissue. After the second transplantation, the outgrowth still consisted of mostly FBs, but distinctly bipolar ScC-like cells could be seen near the explant (Fig. $2 c$ ). These cells made up a small proportion of the migrating cells and did not appear to divide on the plastic substratum. By the third explantation, the bipolar cells made up approximately half of the population of cells emerging from the explant (Fig. $2 d$ ), but because they did not divide rapidly on plastic they were quickly outnumbered by FBs. After four to five explantations (5-6 weeks), the cells surrounding the explants consisted primarily of ScC-like cells (Fig. $2 e$ ) that continued to migrate out of the explant with time (Fig. $2 f$ ). At this point, the explants were enzymatically dissociated and plated onto polylysine-coated dishes. Schwann cells on polylysinecoated dishes exhibited a more extreme bipolar morphology than those that had migrated out of the explant onto bare plastic. Some cells were treated with anti-Thy-1.1 and rabbit complement to lyse remaining FBs; complement-mediated lysis did not appear to improve the $\mathrm{ScC} / \mathrm{FB}$ ratio significantly but did decrease total cell yield (see Table 1). The cell yield decrease was probably due to cells being lost during the extra rinses involved in the process, as well as possible nonspecific actions of complement on the ScCs. The ScCs took on a typical bipolar morphology within $1 \mathrm{~d}$ of plating and stained brightly for $\mathrm{S} 100$ (Fig. $1 c, d)$.

\section{Response to mitogens}

When ScCs purified from adult peripheral nerve by the multiple explantation method were plated onto DRG neurite cultures, the ScCs rapidly associated with the neurites in preference to the underlying collagen. Cells that settled onto collagen near neurites extended processes and migrated onto the neurites. ScCs remained on the neurites and proliferated with a doubling time of 3-4 d. Immunofluorescent staining following a 24-hr pulse of BrdU resulted in a labeling index of $33.2 \%$ (a labeling index of $22.6 \%$ was observed in more densely populated areas; Fig. $3 a, b$; Table 2). Isolated adult-derived ScCs also proliferated in response to GGF and forskolin (see Table 2). Within 3-4 d of exposure to GGF and forskolin, the ScCs began to divide and take on the flattened polymorphic morphology with larger flattened FB-like nuclei seen in GGF-driven perinatal ScCs (Porter et al., 1986) but retained $\mathrm{S} 100$ immunoreactivity (data not shown). Cell numbers doubled in 3-4 d, and a 24-hr BrdU labeling index of $26.6 \%$ ( $13.0 \%$ in confluent areas) was observed (Fig. 3c.d; Table 2).

Evidence of transformation. To indicate whether the $\mathrm{ScCs}$ had retained proliferative control, some cells from each group were plated onto polylysine-coated tissue culture plastic in the absence of any added mitogens. Cells previously driven to divide by neurite contact became quiescent and assumed a bipolar spindle-shaped morphology. Three to four weeks after the removal of mitotic stimuli, the cells were pulsed for $24 \mathrm{hr}$ with BrdU-containing medium, stained, and examined closely for evidence of clonal multiplication. Labeled cells that had been expanded on neurites were not seen to be growing in colonies, suggesting that the dividing cells were not the result of clonal multiplication of transformed cells. Labeling indices as high as $5.6 \%$ were seen at some time points, but this did not appear to indicate early transformation since at later time points labeling indices in comparable cultures were near zero (see Table 2). We therefore believe that these cells had not transformed. Embryonic ScCs prepared by the method of Wood (1976) have been

\begin{tabular}{lcll}
\hline Table 2. Tests for retention of proliferative control & & \\
Stimulus & $\begin{array}{l}\text { Duration of } \\
\text { stimulus (weeks) }\end{array}$ & $\begin{array}{l}\text { LI during } \\
\text { stimulation }\end{array}$ & $\begin{array}{l}\text { LI 3-4 weeks after } \\
\text { stimulus removal }\end{array}$ \\
\hline DKG neurites & 7 & & $2.4 \%$ \\
& 9 & $33.2 \%$ & $4.1 \%$ \\
& 12 & & $5.6 \%$ \\
& 22 & & $0.2 \%$ \\
GGF/forskolin & 28 & & $0.0 \%$ \\
& 7 & & $0.0 \%$ \\
& 18 & $0.0 \%$ \\
& 20 & $12.8 \%$ (colonies $\leq 41 \%)$ \\
& 24 & $4.0 \%$ (colonies $\leq 30 \%$ ) \\
& 30 & $26.6 \%$ & $12.3 \%$ (evenly dispersed)
\end{tabular}

\footnotetext{
${ }^{a}$ Labeling index (LI) is given as the percentage of BrdU-positive cells following a 24-hr pulse of $10 \mu \mathrm{M}$ BrdU.
} 

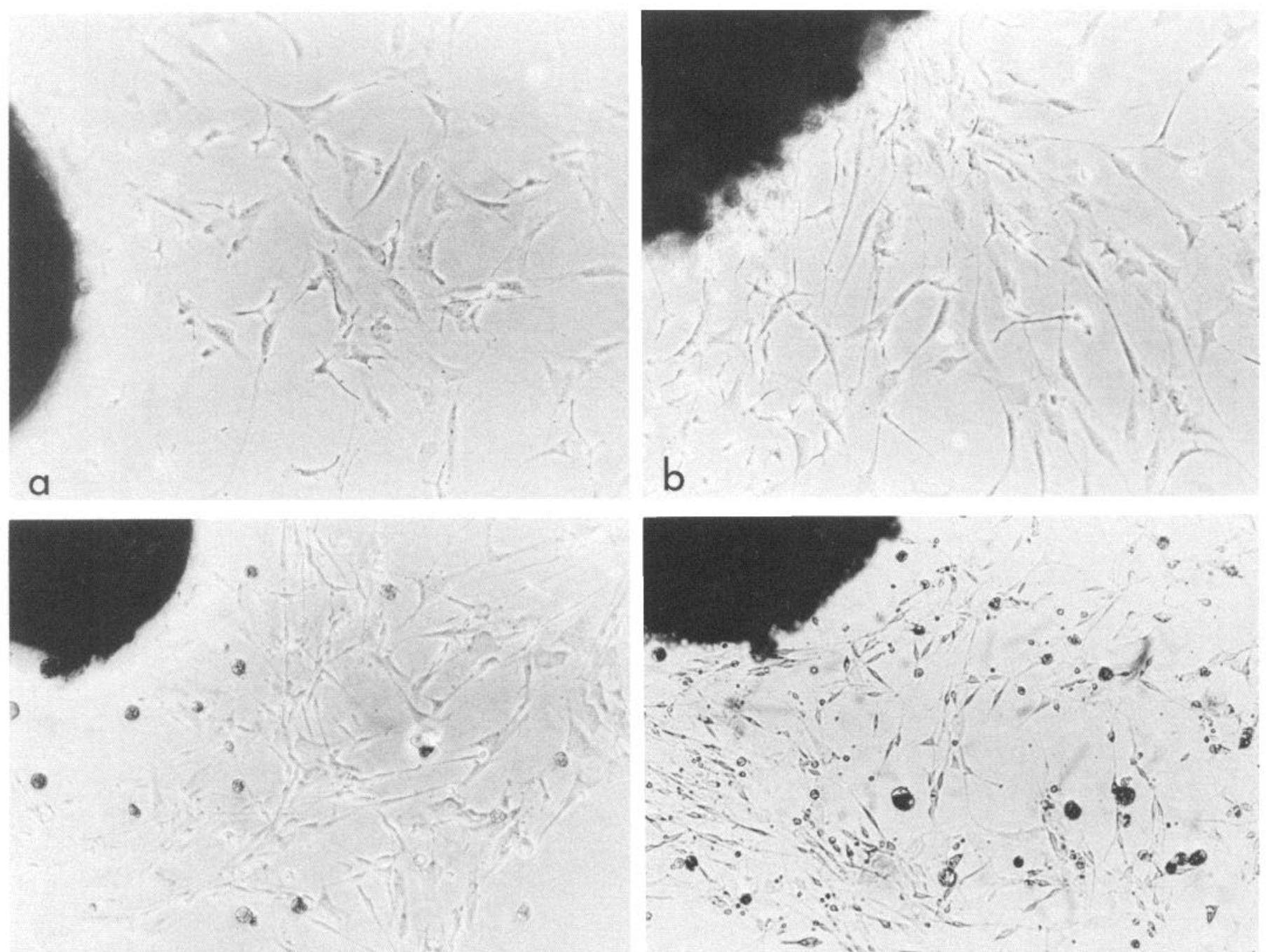

C
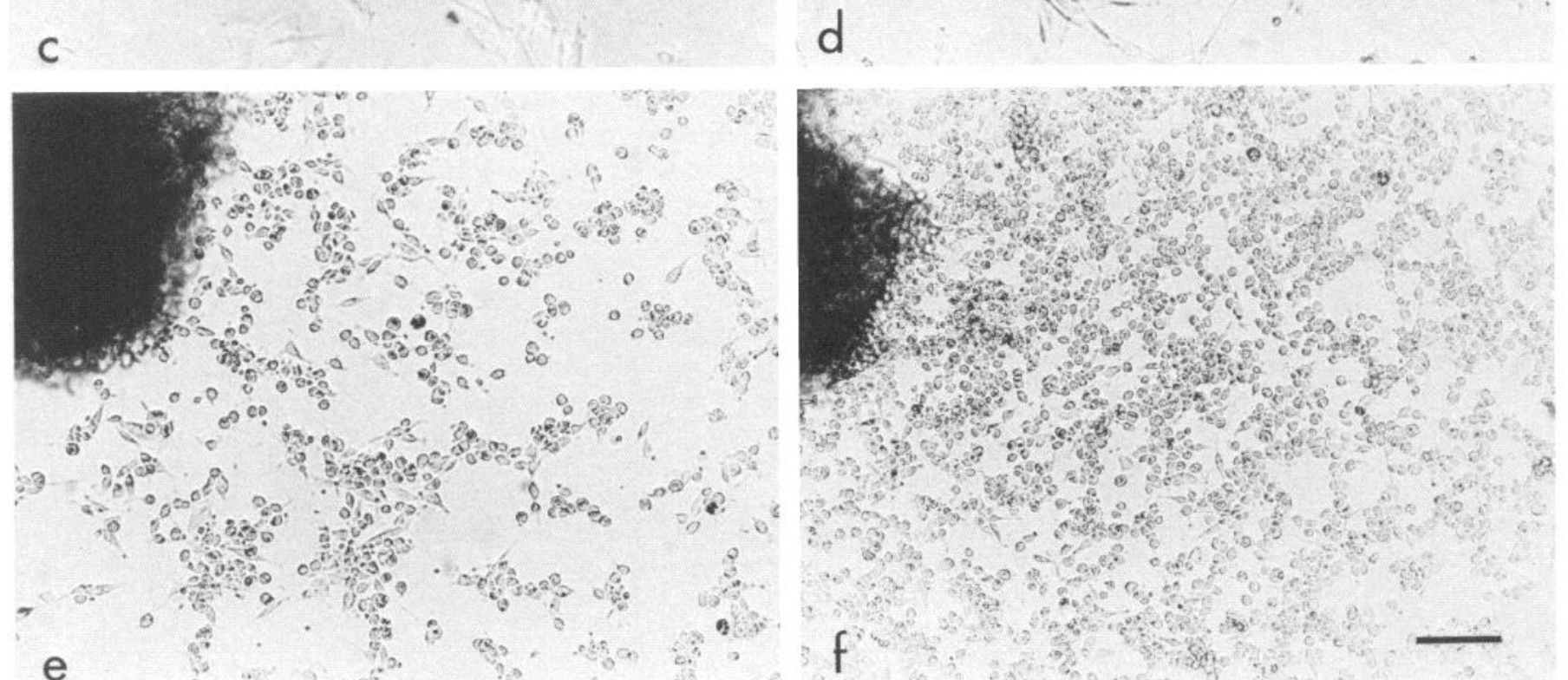

Figure 2. Representative cellular outgrowth from adult rat sciatic nerve explants in culture. Explants show outgrowth that consists primarily of fibroblasts by $3-4 \mathrm{~d}$ in culture $(a)$ and constitutes a near monolayer of cells by $7-10 \mathrm{~d}(b)$. Successive serial explantations $(c$ and $d)$ show a reversal of the $\mathrm{ScC}$ /fibroblast ratio. Further explantations produce outgrowth consisting almost exclusively of ScCs (e), and the populations expand with time $(f)$. Because rat ScCs on tissue culture plastic do not show characteristic morphology, it is necessary to use $\mathbf{S} 100$ immunostaining to establish their identity (cf. Fig. 1). Scale bar, $100 \mu \mathrm{m}$. 

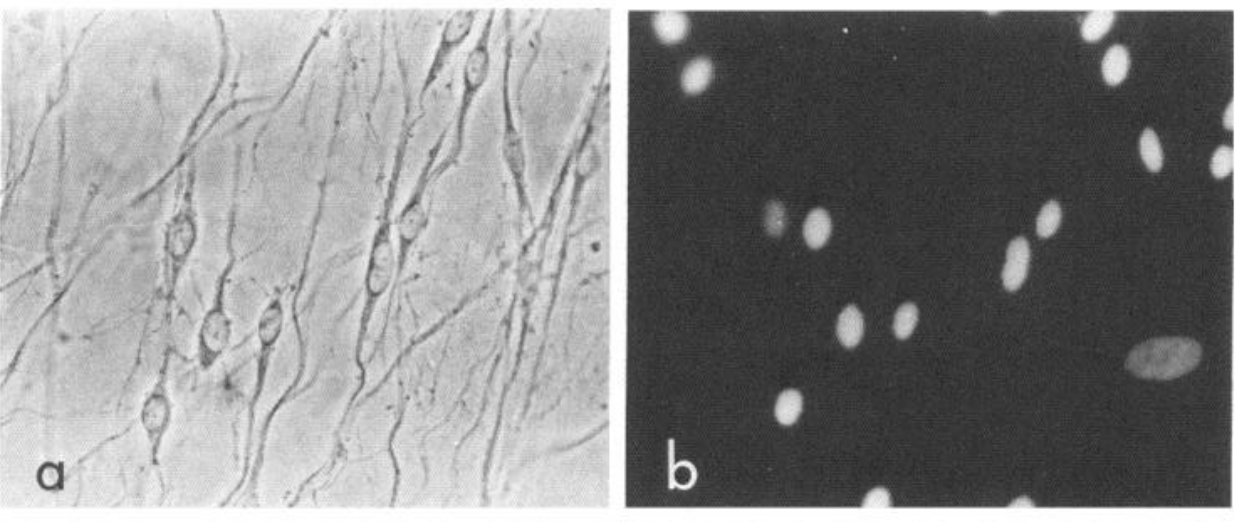

Figure 3. Adult-derived ScCs incorporate BrdU when stimulated to divide by contact with sensory neurites ( $a$ and $b$ ) or when isolated ScCs are cultured in the presence of GGF and forskolin $(c$ and $d)$. Corresponding fields show phase contrast images ( $a$ and $c$ ) and BrdU labeling $(b$ and $d$ ) of cells that have synthesized DNA during a 24-hr BrdU pulse. ScCs on neurites elongate, and nuclear morphology clearly differs from that of the occasional FB $(b$, lower right), whereas ScCs on GGF/forskolin flatten with a consequent change in nuclear morphology. Scale bar, $25 \mu \mathrm{m}$.
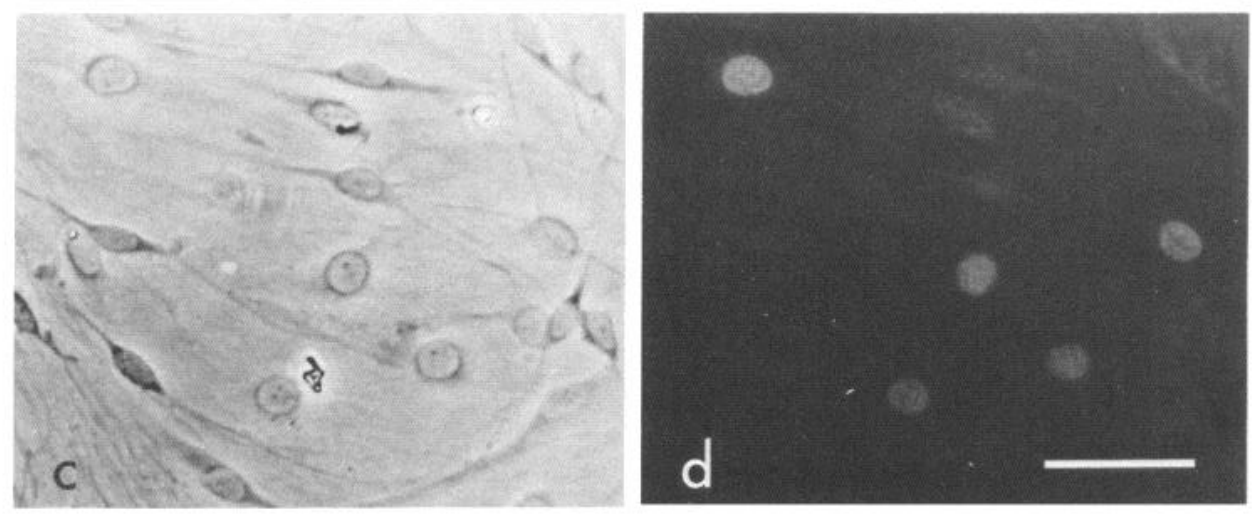

expanded on neurites for over a year without evidence of transformation (Valerie Obremski, unpublished observations).

During early passages, GGF- and forskolin-driven cells showed no evidence of transformation. These cells retained their polymorphic appearance for as long as 2 weeks after removal of growth factors. The labeling index at $10 \mathrm{~d}$ after cessation of a 12 -week exposure to GGF/forskolin remained at $18.1 \%$. By 34 weeks after stimulus removal, these $\mathrm{ScCs}$ assumed the typical spindle-shaped morphology and showed BrdU labeling indices of less than $1 \%$. Only after 12-18 weeks of continuous exposure to GGF/forskolin did the cells show evidence of transformation, indicated by the persistence of proliferation (appearance of colonies of ScCs with labeling indices up to $41 \%$; Table 2) when mitogens were withdrawn. The time course of the occurrences of transformation was similar to that seen for GGF/forskolin driven embryonic ScCs (Porter et al., 1986). Unless specifically noted, further findings regarding GGF-driven cells will be restricted to early passages where transformation had not occurred.

\section{Functionality assessment}

Myelination. When cells from either the neurite- or GGFdriven groups were plated onto neurites, they were seen to line up along the neurites and proliferate. Fully populated cultures were switched to a myelination supporting medium containing ascorbate and 15\% FCS (Eldridge et al., 1987). Within the first week, the ScCs flattened out on the neurites, extending processes along the axons. Myelin, appearing as thickened phase-dark segments along the neurites, was first observed in 10-14 d; the number of myelin segments increased with time. In Sudan blackstained preparations, thickened myelin segments and nodes of Ranvier were evident (Fig. $4 a$ ). Immunostaining with $\mathrm{P}_{0}$, a my- elin-specific marker, also demonstrated myelination (Fig. $4 b, c$ ). Electron microscopy of myelinated cocultures showed characteristic myelin lamellae and a complete basal lamina surround (Fig. 4d). Populations of ScCs that contained transformed cells were not seen to myelinate neuronal cultures, similar to observations by Porter et al. (1987).

Support of CNS neurite outgrowth. Explants of E-15 rat retina were plated onto beds of adult ScCs to assess the ability of the ScCs to support neurite outgrowth. Retinal neurons extended neurites beyond the margin of the explant by the second day in culture. On ScC beds, explants extended processes preferentially onto the $\mathrm{ScCs}$ and did not grow onto the underlying ammoniated collagen substratum in areas that did not contain ScCs (Fig. 5a). Ammoniated collagen alone did not support retinal neurite outgrowth. ScCs that were contacted by growing axons appeared to migrate onto and associate with neurites. Immunostaining with neurofilament antibodies showed that many of the linear cordons of ScCs emanating from the explants contained neuronal processes. Neurites extended radially and reached maximum distances of 5-6 mm from the edge of the explants in 5 d. Some migration of cells was seen from the explants. These cells were S100-negative and are believed to be FBs or macrophages (Kleitman et al., 1988). Fluorescence imaging of the neurofilaments revealed that the neurites were growing in association with the ScCs (Fig. $5 b$ ).

\section{Human tissue}

To determine the extent of applicability of these techniques to human tissues, we attempted to isolate $\mathrm{ScCs}$ from adult human phrenic nerve. Immediate dissociation of human nerve yielded cell populations that were rich in FB-like cells. By contrast, using the multiple explantation techniques described above, we have 

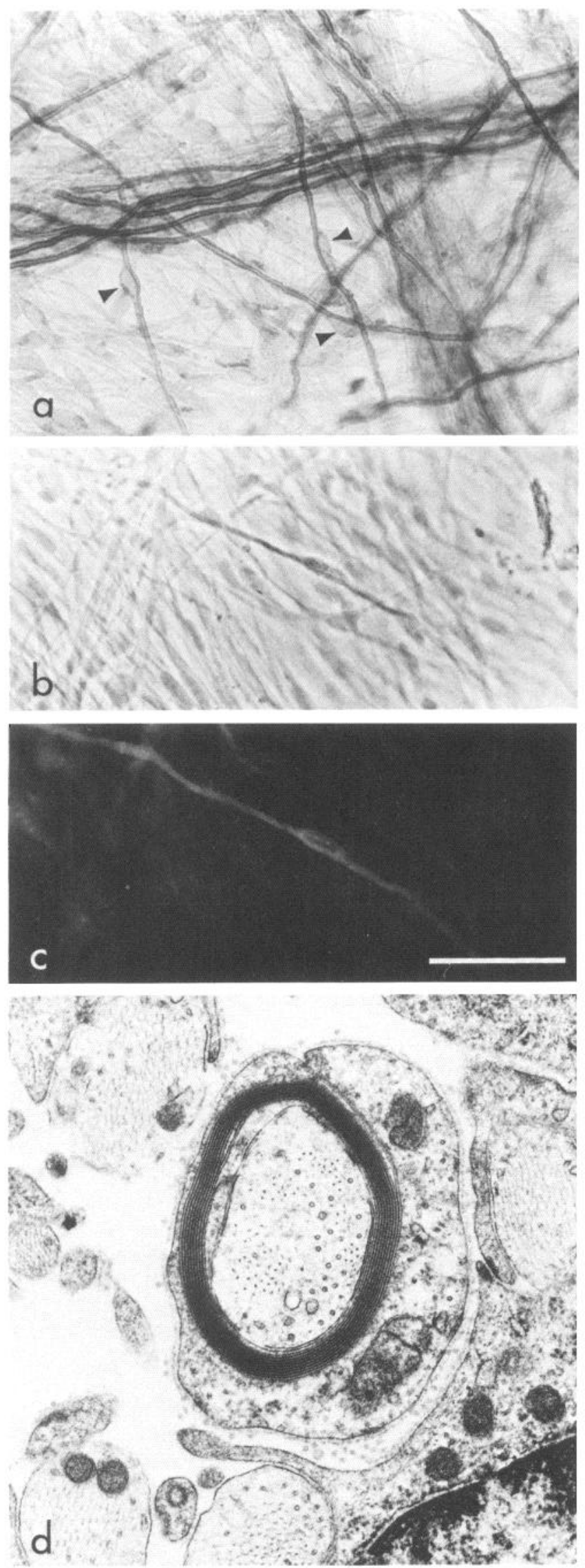
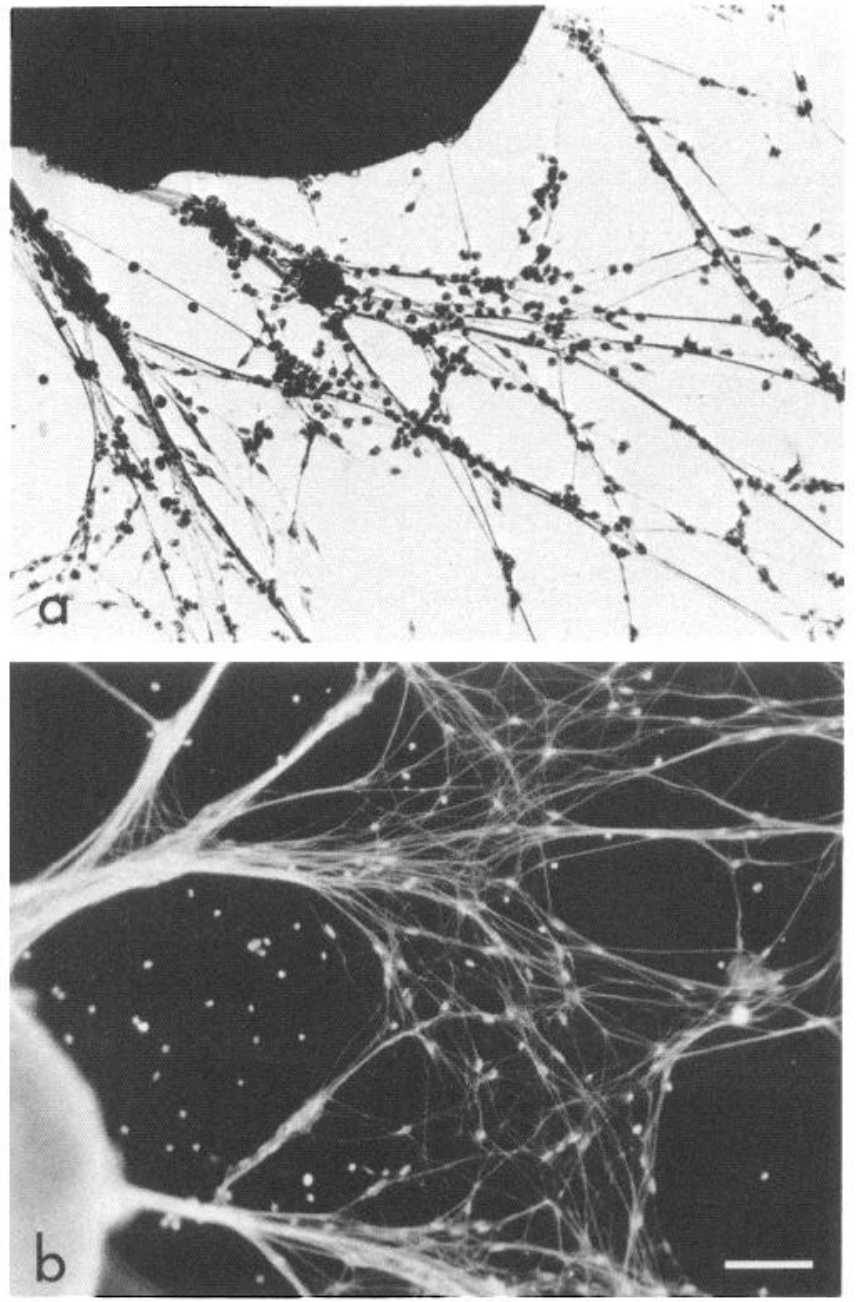

Figure 5. Adult-derived ScCs support neurite outgrowth from retinal explants from 15-d rat embryos. Sudan black staining $(a)$ shows fascicles of neurites and ScCs. Neurofilaments in these fascicles are shown by SMI-31 immunostaining $(b)$. Scale bar, $100 \mu \mathrm{m}$.

isolated populations of human $\mathrm{ScCs}$ that were $98 \%$ pure at yields of nearly $2 \times 10^{4}$ cells $/ \mathrm{mg}$ of nerve. Human phrenic nerve exhibited many of the same characteristics as the rat sciatic nerve, albeit with a slightly slower time course. Within the first week of culture, FBs could be seen migrating from the explants. Serial explantation eventually produced explants whose migratory cells consisted of a higher percentage of ScCs, but with human tissue the ratio of ScCs to FBs migrating from the explant never became as high as in the rat preparations. Dissociation of the human explants, after 6-7 weeks in vitro, yielded highly purified populations of ScCs. The ScCs demonstrated typical bi- or tripolar morphology, had oval nuclei, and stained brightly

Figure 4. Adult-derived $\mathrm{ScCs}$ retain the ability to myelinate neuronal processes. Sudan black staining for myelin (a) shows ScC nuclei ( $a r-$ rowheads) adjacent to myelin segments. Myelin segments apparent with phase contrast optics $(b)$ immunostain positively for the myelin-specific marker $\mathbf{P}_{0}(c)$. At the ultrastructural level, myelin formed by adultderived $\mathrm{ScC}$ s shows typical lamella and a surround of continuous basal lamina $(d)$. Scale bar, $50 \mu \mathrm{m}(a-c)$. 


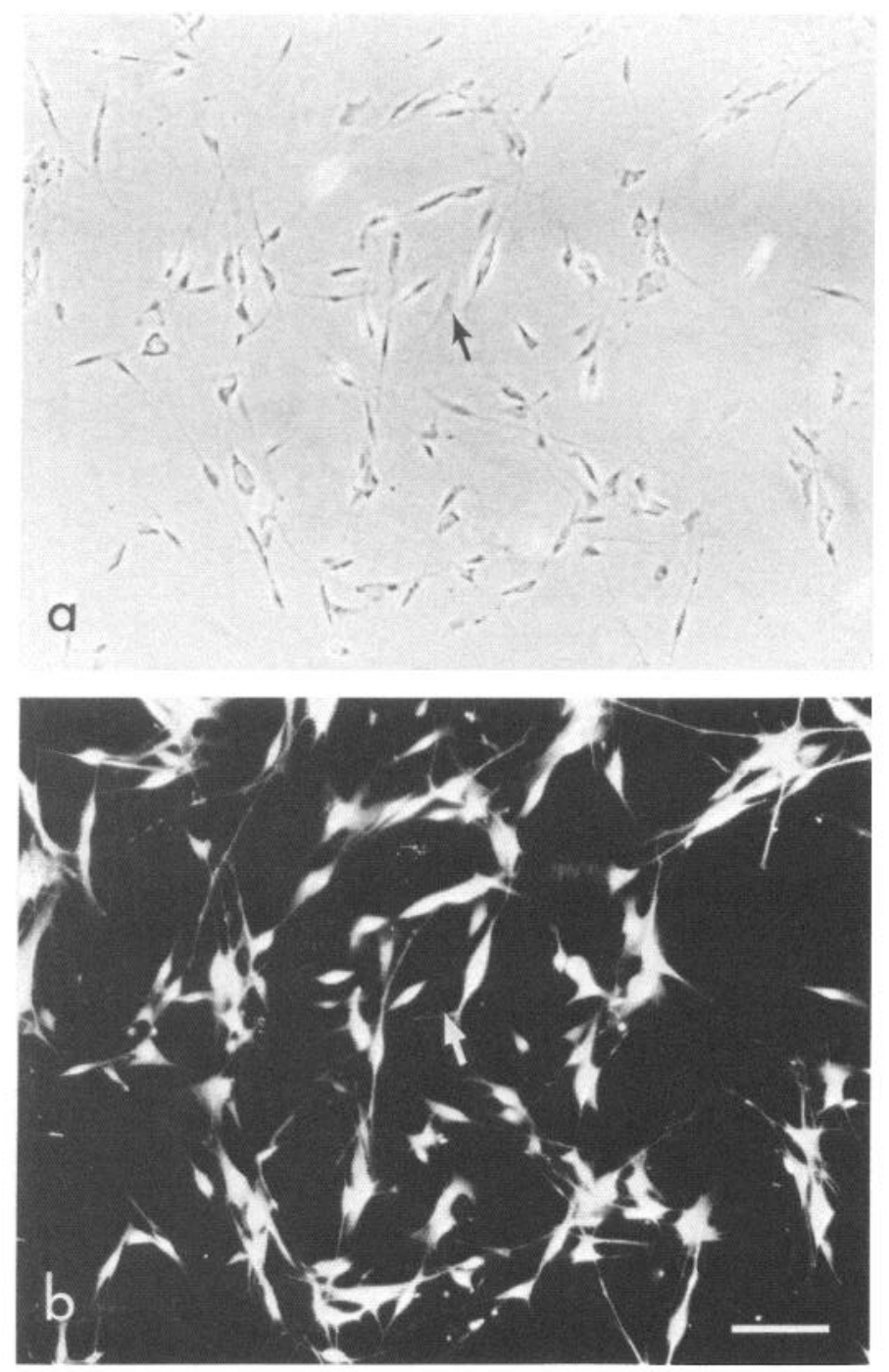

Figure 6. Adult-derived $\mathrm{ScCs}$ isolated from human phrenic nerve explants following five explantations during 7 weeks. Cells exhibit typical bipolar morphology $(a)$ and stain brightly for $\mathrm{S} 100(b)$. Note occasional unstained FB (arrows). Scale bar, $100 \mu \mathrm{m}$.

for $\mathrm{S} 100$ (Fig. $6 a, b$ ). At present, we have not used complementmediated lysis to remove residual FBs, and thus the small population of FBs ultimately proliferate and begin to outnumber the ScCs if left untreated. Treatment for $4 \mathrm{~d}$ with the antimitotic agent cytosine arabinoside $\left(10^{-5} \mathrm{M}\right)$ produced cultures that could be kept for weeks in serum-containing medium before significant numbers of FBs began to divide.

\section{Discussion}

ScCs serve as highly permissive substrata for growth of several types of CNS neurons in culture (Noble et al., 1984; Fallon 1985a,b; Ard et al., 1987; Bixby et al., 1988; Kleitman et al., 1988 ). Such outgrowth promotion is specific to ScC surfaces as it is not observed on FB surfaces (Fallon, 1985a,b; Kleitman et al., 1988) or in the presence of glial cell-conditioned medium (Fallon, 1985a). Although the peripheral nerve grafts tested in transplantation paradigms contain extracellular matrix (ECM) components, FBs, ScCs, and other cell types, in at least some CNS systems, neurite growth is not supported when ScCs are removed (Hall, 1986; Keynes, 1987; Kromer and Cornbrooks,
1987; Smith and Stevenson, 1988). This dependence on ScCs may be related to neurite-promoting ligands on $\mathrm{ScC}$ surfaces. Some evidence, however, indicates an early role of a soluble tropic factor in inducing the initial sprouting by injured axons (Kuffler, 1986; Kromer and Cornbrooks, 1987; Kuffler, 1989). The demonstration that peripheral grafts support the axonal growth from CNS areas such as the spinal cord (David and Aguayo, 1981) suggests that the transplantation of PNS components into injured spinal cord could foster recovery following spinal cord injury.

If $\mathrm{ScCs}$ are to be useful for autologous grafting into patients with spinal cord injury, it will be necessary to have a reliable method for procuring large pure populations of ScCs from relatively small samples of peripheral nerve. This would make it possible to obtain tissue from a biopsy of a peripheral sensory nerve, such as the sural nerve, purify and amplify the $\mathrm{ScC}$ population, and transplant ScCs into or near a spinal cord lesion site. Because the majority of spinal cord injuries occur in young adults, techniques to procure pure populations of $\mathrm{ScCs}$ from adult sources will have to be established. We have demonstrated here that we are able to obtain nearly pure populations of ScCs from both adult derived rat and human peripheral nerve and, furthermore, that in the case of the rat cells we are able to amplify substantially these cells without hindering their functional capacity. We believe an additional distinct advantage of this method is its reproducibility.

While the multiple explantation technique described here has the drawback of requiring a long culture period, the high proportion of FB-derived tissue in adult peripheral nerve precludes being able to extract purified ScCs by direct dissociation of the nerve. Scarpini et al. (1988) have reported obtaining cultures of ScCs with $92 \%$ purity by dissociating adult rat sciatic nerve immediately after removal from the animal and report ScC yields of about 600 cells $/ \mathrm{mg}$ nerve. In our preparations, immediate dissociation of adult rat sciatic nerve yielded approximately $1000 \mathrm{cells} / \mathrm{mg}$ nerve, and only $10-40 \%$ of these appeared to be ScCs based on S100 staining and cell soma and nuclear morphology. We attempted to replicate the procedures of Scarpini et al. (1988) as closely as possible. To replate the cells following enzymatic digestion and centrifugation, we found it necessary to triturate the pellet, a step that was not described by Scarpini et al. (1988). Aside from the second trituration, we believe the only other procedural difference between the processes was the use of Sprague-Dawley rats in the present studies (versus Lewis rats).

The tremendous increase in $\mathrm{ScC}$ yield obtained after the explantation period compensates for the delay imposed by the multiple explantation technique. We believe the improved $\mathrm{ScC}$ yield (which can be greater than 100 times that observed after immediate dissociation) to be due to several factors: (1) by allowing the more motile FBs to migrate from the explant, we decrease the ratio of FBs to ScCs in the tissue; (2) many ScCs are probably lost during immediate dissociation as a result of mechanical damage to cell processes that tightly wrap axonal segments (the ScCs in explants have an opportunity to withdraw from their processes gradually); and (3) by allowing time for a form of in vitro Wallerian degeneration to proceed in the explants, we are able to capitalize on the intrinsic ability of ScCs to multiply in response to axolemmal and myelin debris (Salzer and Bunge, 1980; Crang and Blakemore, 1986). When Wallerian degeneration occurs in vivo, it is accompanied by the invasion of the nerve by other nonglial cells, specifically macrophages, 
which may themselves stimulate the proliferation of ScCs (Beuche and Friede, 1984; Bigbee et al., 1987; Baichwal et al., 1988; for review, see Fawcett and Keynes, 1990). In our hands, the relative absence of macrophages from the nerve explants did not prevent expansion of the $\mathrm{ScC}$ population [frozen sections of rat sciatic nerve explants after $21 \mathrm{~d}$ in vilro show BrdU labeling indices of $6.2 \%$ (T. K. Morrissey, N. Kleitman, and R. P. Bunge, unpublished observations)], but it does avoid the need to subsequently remove other cell types to obtain pure populations of ScCs.

If adult cells are to be used for transplantation experiments, it is necessary to ensure that they retain the capability to associate with neurites and respond to neuronal signals to proliferate, differentiate, and myelinate. In coculture with DRG neurites, the adult $\mathrm{ScCs}$ proliferated and myelinated at rates similar to those seen in cclls obtained from the perinatal animals (Wood and Bunge, 1975; Ratner et al., 1986). Furthermore, adult-derived ScCs retained the ability to support the growth of neurites from retinal ganglion cells in vitro. The ability to support axonal regeneration in the CNS is an important goal in the development of adult ScCs for transplantation.

The ability of these cells to be amplified through several generations and still retain functional capacity is crucial if they are to be obtained from a small nerve biopsy, amplified in culture, and then be transplanted back into the donor. At the time of this writing, the cells had been carried on neurons for over 8 months and 50-60 generations without evidence of transformation, and these cells retained the ability to associate with and multiply on neurites as well as to myelinate neurites under appropriate culture conditions. However, cells that were stimulated to divide on $\mathrm{GGF} /$ forskolin began to show evidence of transformation by 18 weeks in culture. Langford et al. (1988) have demonstrated that immortalized embryo-derived Schwann cells, when transplanted into animals, are capable of forming tumors. Future experiments employing adult-derived Schwann cells in transplantation paradigms must be monitored closely for evidence of tumor formation. While there is a limit to the extent that adult-derived $\mathrm{ScCs}$ can be expanded on chemical mitogens, there appears to be a window during which large numbers of $\mathrm{ScCs}$ can be generated while retaining growth control (in clinical circumstances, it is unlikely that there would be enough time between harvest and reimplantation for the cells to be driven to transformation). By this method, after mitogenic stimulation for 10 passages, one $3.5-\mathrm{cm}$ length of adult rat sciatic nerve will yield on the order of one billion Schwann cells.

We were gratified to observe that these techniques appear to be applicable to human tissue. Human phrenic nerve was chosen for these experiments over nerves from the leg because it was easily accessible to the transplant team during procurement of other organs for transplantation. In vitro studies (Mirsky and Jessen, 1986), as well as nerve grafting experiments (Aguayo et al., 1976), have indicated that the differences seen between myelinating and nonmyelinating $\mathrm{ScC}$ s are primarily a function of the ScC's associated axon, rather than being intrinsic to the $\mathrm{ScC}$ itself. Therefore, we have no reason to believe that ScCs from other human peripheral nerves should behave differently than those from phrenic nerve. Pleasure et al. (1986) have shown that both axolemmal fractions and GGF are mitogens for Schwann-like cells isolated from human neurofibromas. Our initial experience in attempting to expand $\mathrm{ScC}$ populations derived from adult human nerve indicated that human Schwann cells may not be responsive to some of the mitogens known to stimulate rat Schwann cell proliferation or that the required concentrations of these mitogens might be different for humanderived Schwann cells (Morrissey et al., unpublished results). Further experiments are needed to clarify these differences.

We are presently employing expanded populations of $\mathrm{ScCs}$ prepared from neonatal rat nerve in implants placed into spinal cord lesions in adult rats (Paino and Bunge, 1990). These experiments have demonstrated that implants containing pure populations of ScCs are effective in eliciting regrowth of axons from the host cord and that these regenerated axons are ensheathed and myelinated by the implanted cells. Experiments are also underway to determine if cells prepared by this method function similarly when used to bridge gaps in peripheral nerve trunks. It will be necessary to repeat these experiments with Schwann cells expanded from adult nerve (by the method described above) in order to establish that the concept of autotransplantation of expanded $\mathrm{ScC}$ populations taken from and reimplanted into mature mammals is tenable.

\section{References}

Aguayo AJ, Charron L, Bray GM (1976) Potential of Schwann cells from unmyelinated nerves to produce myelin: a quantitative ultrastructural and radiographic study. J Neurocytol 5:565-573.

Ard MD, Bunge RP, Bunge MB (1987) Comparison of the Schwann cell surface and Schwann cell extracellular matrix as promoters of neurite growth. J Neurocytol 16:539-555.

Askanas V, Engel WK, Dalakas MC, Lawrence JV, Carter LS (1980) Human Schwann cells in tissue culture. Arch Neurol 37:329-337.

Baichwal RK, Bigbee JW, DeVries GH (1988) Macrophage-mediated myelin-related mitogenic factor for cultured Schwann cells. Proc Natl Acad Sci USA 85:1701-1705.

Beuche W, Friede RL (1984) The role of non-resident cells in Wallerian degeneration. J Neurocytol 13:767-796.

Bighee JW, Yoshino JE, DeVries GH (1987) Morphological and proliferative responses of cultured Schwann cells following rapid phagocytosis of a myelin-enriched fraction. J Neurocytol 16:487-496.

Bixby JL, Lilien J, Reichardt LF (1988) Identification of the major proteins that promote neuronal process outgrowth on Schwann cells in vitro. J Cell Biol 107:353-361.

Bottenstein JE, Sato GH (1979) Growth of a rat neuroblastoma cell line in serum-free supplemented medium. Proc Natl Acad Sci USA 76:514-517.

Brockes JP, Fields KP, Raff MC (1979) Studies on cultured rat Schwann cells. I. Establishment of purified populations from cultures of peripheral nerve. Brain Res 165:105-108.

Bunge RP (1986) The cell of Schwann. In: Diseases of the nervous system (Asbury AK, McKhann GM, McDonald WI, eds), pp 153162. Philadelphia: Saunders.

Bunge RP, Hopkins JM (1990) The role of peripheral and central neuroglia in neural regeneration in vertebrates. Sem Neurosci 2:509. 518.

Bunge RP, Eldridge CF, Ard MD, Kleitman N (1988) Schwann cell contact as a factor in neuronal trophic support and the promotion of neurite growth. In: Neurobiology of amino acids, peptides, and trophic factors (Ferrendelli JA, Collins RC, Johnson EM, eds), pp $115-$ 126. Boston: Kluwer.

Bunge MB, Wood PM, Tynan LB, Bates ML, Sanes JR (1989) Perineurium originates from fibroblasts: demonstration in vitro with a retroviral marker. Science 243:229-231.

Crang AJ, Blakemore WF (1986) Observations on Wallerian degeneration in explant cultures of cat sciatic nerve. J Neurocytol 15:471482.

David S, Aguayo AJ (1981) Axonal elongation into peripheral nervous system "bridges" after central nervous system injury in adult rats. Science 214:931-933.

Eldridge CF, Bunge MB, Bunge RP, Wood PM (1987) Differentiation of axon-related Schwann cells in vitro. I. Ascorbic acid regulates basal lamina assembly and myelin formation. J Cell Biol 105:1023-1034.

Fallon JR (1985a) Neurite guidance by non-neuronal cells in culture: preferential outgrowth of peripheral neurites on glial cells as compared to non-glial cell surfaces. J Neurosci 5:3169-3177

Fallon JR (1985b) Preferential outgrowth of central nervous system 
neurites on astrocytes and Schwann cells as compared with nonglial cells in vitro. J Cell Biol 100:198-207.

Fawcett JW, Keynes RJ (1990) Peripheral nerve regeneration. Annu Rev Neurosci 13:43-60.

Hall SM (1986) Regeneration in cellular and acellular autografts in the peripheral nervous system. Neuropathol Appl Neurobiol 12:2746.

Keynes RJ (1987) Schwann cells during neuronal development and regeneration: leaders or followers? Trends Neurosci 10:137-139.

Kleitman N, Wood P, Johnson MI, Bunge RP (1988) Schwann ccll surfaces but not extracellular matrix organized by Schwann cells support neurite outgrowth from embryonic rat retina. J Neurosci 8:653663.

Kromer LF, Cornbrooks CJ (1985) Transplants of Schwann cell cultures promote axonal regeneration in the adult mammalian brain. Proc Natl Acad Sci USA 82:6330-6334.

Kromer LF, Cornbrooks CJ (1987) Identification of trophic factors and transplanted cellular environments that promote CNS axonal regeneration. Ann NY Acad Sci 495:207-224.

Kuffler DP (1986) Isolated satellite cells of a peripheral nerve direct the growth of regenerating frog axons. J Comp Neurol 249:57-64.

Kuffler DP (1989) Regeneration of muscle axons in the frog is directed by diffusable factors from denervated muscle and nerve tubes. J Comp Neurol 281:416-425.

Langford LA, Porter S, Bunge RP (1988) Immortalized rat Schwann cells produce tumors in vitro. J Neurocytol 17:521-529.

Mirsky R, Jessen KR (1986) The biology of non-myelin-forming Schwann cells. Ann NY Acad Sci 486:132-146.

Noble M, Juin F-S, Cohen J (1984) Glia are a unique substrate for the in vitro growth of central nervous system neurons. J Neurosci 4: 1892-1903.

Paino CP, Bunge MB (1990) Axon growth into implants of Schwann cells placed in lesioned spinal cord. Soc Neurosci Abstr 16:1282.
Pleasure D, Kreider B, Sobue G, Ross AH, Koprowski H, Sonnenfeld KH, Rubenstein AE (1986) Schwann-like cells cultured from human dermal neurofibromas. Ann NY Acad Sci 486:227-240.

Porter S, Clark MB, Glaser L, Bunge RP (1986) Schwann cells stimulated to proliferate in the absence of neurons retain full functional capacity. J Neurosci 6:3073-3078.

Porter S, Glaser L, Bunge RP (1987) Release of autocrine growth factor by primary and immortalized Schwann cells. Proc Natl Acad Sci USA 84:7768-7772.

Ratncr N, Bunge RP, Glaser L (1986) Schwann cell proliferation in vitro: an overview. Ann NY Acad Sci 486:170-181.

Reddy NB, Askanas V, Engel WK (1982) Demonstration of 2',3-cyclic nucleotide 3 '-phosphohydrolase in cultured human Schwann cells. J Neurochem 39:887-889.

Richardson PM, McGuinness UM, Aguayo AJ (1980) Axons from CNS neurons regenerate into PNS grafts. Nature 284:264-265.

Salzer JL, Bunge RP (1980) Studies of Schwann cell proliferation. I. An analysis in tissue culture of proliferation in development, Wallerian degeneration, and direct injury. J Cell Biol 84:739-752.

Scarpini E, Kreider BQ, Lisak RP, Pleasure DE (1988) Establishment of Schwann cell cultures from adult peripheral nerves. Exp Neurol 102:167-176.

Smith GV, Stevenson JA (1988) Peripheral nerve grafts lacking viable Schwann cells fail to support central nervous system axonal regeneration. Exp Brain Res 69:299-306.

Wood PM (1976) Separation of functional Schwann cells and neurons from normal peripheral nerve tissue. Brain Res 115:361-375.

Wood PM, Bunge RP (1975) Evidence that sensory axons are mitogenic for Schwann cells. Nature 256:662-664.

Yong VW, Kim SU (1987) A new double labelling immunofluorescence technique for the determination of proliferation of human astrocytes in culture. J Neurosci Methods 21:9-16. 